\title{
IL-6 and INF- $\gamma$ levels in patients with brucellosis in severe epidemic region, Xinjiang, China
}

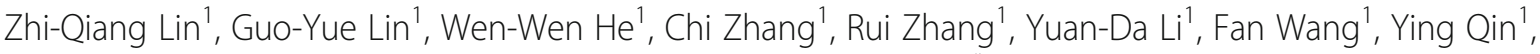 \\ Li Duan', Dou-Dou Zhao', Xiao-Juan Qu', Hui Gao ${ }^{1}$ and Hai Jiang ${ }^{2^{*}}$
}

\begin{abstract}
Background: The incidence of brucellosis, which is caused by the Brucella species of bacteria, is rapidly rising worldwide; however, few studies have investigated the immune response to this pathogen and clinical biochemical features. In this paper, we examined the levels of various cytokines and inflammatory factors as well as clinical course characteristics in patients with brucellosis, in order to provide evidence for the diagnosis, assessment, and prognosis of this infectious disease.

Methods: A total of 191 brucellosis inpatients (50 acute cases and 141 chronic cases), as well as 60 healthy control subjects, were included in the analysis. We investigated changes in the levels of six cytokines (IL-4, IL-6, IL-10, IL-17, TNF-a, INF- $\gamma$ ) and related clinical biochemical markers in patients with acute and chronic brucellosis in Xinjiang, China. Possible factors were statistically analyzed using the $t$ test, $\chi^{2}$ test, $z$ test and a multivariate logistic stepwise regression test.

Results: We found that IL-4, IL-6, IL-10, IL-17, IFN- $\gamma$, and TNF-a levels were higher in those with brucellosis than in controls $(P<0.05)$. With regard to disease progression, procalcitonin $(P C T)$ and $C$-reactive protein $(C R P)$ levels were significantly higher in those with an acute infection compared to chronic cases $(P<0.05)$. We found that the expression of all six cytokines tested was closely related to the degree of brucellosis using univariate logistic regression; however, only IL-6 and INF- $\gamma$ levels were independent factors associated with the severity of brucellosis.

Conclusions: Assessing cytokine levels in patients with acute and chronic brucellosis is not only useful for detecting the immune response, but can also be indicative of the severity of brucellosis. In particular, we propose IL-6 and INF- $\gamma$ levels may be useful independent predictive factors in the clinical evaluation and diagnosis of brucellosis.
\end{abstract}

Keywords: Brucellosis, Cytokines, Immunity, IL-6, INF- $\gamma$

\footnotetext{
* Correspondence: jianghai@icdc.cn

${ }^{2}$ State Key Laboratory for Infectious Disease Prevention and Control, Collaborative Innovation Center for Diagnosis and Treatment of Infectious Diseases, National Institute for Communicable Disease Control and Prevention, Chinese Center for Disease Control and Prevention, Beijing, China Full list of author information is available at the end of the article
}

(c) The Author(s). 2020 Open Access This article is licensed under a Creative Commons Attribution 4.0 International License, which permits use, sharing, adaptation, distribution and reproduction in any medium or format, as long as you give appropriate credit to the original author(s) and the source, provide a link to the Creative Commons licence, and indicate if changes were made. The images or other third party material in this article are included in the article's Creative Commons licence, unless indicated otherwise in a credit line to the material. If material is not included in the article's Creative Commons licence and your intended use is not permitted by statutory regulation or exceeds the permitted use, you will need to obtain permission directly from the copyright holder. To view a copy of this licence, visit http://creativecommons.org/licenses/by/4.0/. The Creative Commons Public Domain Dedication waiver (http://creativecommons.org/publicdomain/zero/1.0/) applies to the data made available in this article, unless otherwise stated in a credit line to the data. 


\section{Background}

Brucellosis is a contagious allergic disease caused by the Brucella species of bacteria that is classified as a Class B infectious disease according to the Law of the People's Republic of China on the Prevention and Control of Infectious Diseases [1, 2]. Globally, there are 500000 new cases of brucellosis each year, and the true incidence is always much higher than the reported number of cases [3]. In China, the number of cases of brucellosis has rapidly risen since the mid-1990s [4], and it has become one of the fastest-growing infectious diseases [5]. Brucellosis infection has a chronic disease course, and unfortunately, there is currently no effective human vaccine $[6,7]$.

Brucellosis is widely distributed, with epidemic areas mainly occurring in frontier grassland pastoral areas, where both people and animals are afflicted. Insufficient environmental hygiene, disease prevention measures, and medical conditions often lead to the occurrence, spread, and prolongation of brucellosis [8]. The main epidemic areas of brucellosis in China comprise five pastoral locations: Xinjiang, Inner Mongolia, Qinghai, Ningxia, and Tibet. Xinjiang is a multi-ethnic animal husbandry area, and the annual incidence of brucellosis in high-risk professional populations (farmers, herdsmen and veterinarians) is about $6.4-7.6 \%$ [9]. To date, research on brucellosis in China has mainly focused on epidemiological investigations $[10,11]$, with only a few studies investigating the cytokine immune response to this pathogen. In particular, Han et al. [12] reported that high levels of the cytokine interferon (IFN- $\gamma$ ) may be a characteristic of brucellosis chronicity. However, the relationships between the various cytokines and inflammatory factors and the clinical course of brucellosis have not yet been reported.

In this paper, we examined the levels of various cytokines and inflammatory factors as well as clinical course characteristics in patients with brucellosis, in order to provide evidence for the diagnosis, assessment, and prognosis of this infectious disease.

\section{Methods}

\section{Study design and subjects}

This was a retrospective study of 191 brucellosis patients selected in Sixth People's Hospital of Urumqi from August 2017 to November 2018, including 50 acute cases (less than three months) and 141 chronic cases (more than six months). Patients with a clear clinical history and experimental diagnosis were included. Sixty healthy residents living in the affected areas were selected as the control group. All subjects provided informed consent to participate in the study. Diagnostic criteria were in strict accordance with the "Diagnostic Criteria for Brucellosis (WS 269-2019)” ([13], Supplementary material).

\section{Specimen collection}

A total of $3-4 \mathrm{ml}$ of venous blood was collected and centrifuged at $1200 \times g$ for $5 \mathrm{~min}$. The serum was then removed and stored at a temperature range of $4{ }^{\circ} \mathrm{C}$ to $20{ }^{\circ} \mathrm{C}$ prior to testing.

\section{Cytokine detection}

Using a FACS Calibur flow cytometer (BD, San Diego, USA), we detected six cytokines (IL-4, IL-6, IL-10, IL-17, IFN- $\gamma$, TNF- $\alpha$ ) by using a cytokine detection kit (multiple microsphere flow immunofluorescence method; Qingdao Ruisikeer Biotechnology Co., Ltd. Operation, Qingdao, China) as per the manufacturer's instructions.

\section{Biochemical indicators}

Patients were tested for brucellosis using the rose bengal plate agglutination test, serum agglutination test, and blood culture. We used a Roche Cobas e601 automatic analyzer (Roche, Shanghai, China,) for electrochemiluminescence detection of procalcitonin (PCT), a Siemens ADVIA 2400 automatic analyzer latex (Siemens, Shanghai, China) for enhanced immunoturbidimetric detection of hypersensitive C-reactive protein (CRP), and a Roche Cocha 8000 c701 automatic analyzer (Roche, Shanghai, China) for the immunoturbidimetric detection of rheumatoid factor (RF). We also used an automatic dynamic erythrocyte sedimentation apparatus (model: ORON-200) to detect the erythrocyte sedimentation rate (ESR). Finally, Brucella infection was detected using the BacT/ALERT 3D automatic bacterial/mycobacterial culture detection system. All methods were carried out according to the manufacturer's instructions.

\section{Data analysis}

Statistical analysis was performed using Stata 15.0 (Stata Corp LP, College Station, TX, USA) software. Possible factors were statistically analyzed using the $t$ test, $\chi^{2}$ test and a multivariate logistic stepwise regression test. A $P$ value of $<0.05$ was considered statistically significant.

\section{Results}

\section{Demographic data and clinical characteristics of the} brucellosis patients

The main demographic features of 191 brucellosis cases were shown in Table 1 . Brucellosis patients were mostly male, with the male:female ratio being 2.35. A total of 96 patients $(50.2 \%)$ were aged between 31 and 50 years. There were 84 cases $(44.0 \%)$ of Uygur nationality. Of the 191 patients with brucellosis, 140 were farmers and herdsmen.

Among the 191 patients with brucellosis, 23 (46.0\%) patients in the acute group and $89(63.1 \%)$ in the chronic group had brucellosis arthritis; 23 (46.0\%) patients in the acute group and 76 (54.0\%) in the chronic group had 
Table 1 Demographic features of 191 brucellosis cases

\begin{tabular}{ll}
\hline Demographic features & Number (\%) \\
\hline Sex & $134(70.2 \%)$ \\
Male & $57(29.8 \%)$ \\
Female & \\
Age group (years) & $12(6.3 \%)$ \\
$<20$ & $23(12.0 \%)$ \\
$20-30$ & $40(20.9 \%)$ \\
$31-40$ & $56(29.3 \%)$ \\
$41-50$ & $38(19.9 \%)$ \\
$51-60$ & $22(11.5 \%)$ \\
$61-70$ & \\
Nationality & $84(44.0 \%)$ \\
Uygur & $44(23.0 \%)$ \\
Ha & $43(22.5 \%)$ \\
Han & $11(5.8 \%)$ \\
Hui & $9(4.7 \%)$ \\
Others & \\
Occupation & $140(73.3 \%)$ \\
Farmer \& herdsman & $21(10.1 \%)$ \\
Veterinarians & $30(15.7 \%)$ \\
\hline Others &
\end{tabular}

lumbar disc hyperplasia; 11 (22.0\%) patients in the acute group and $20(14.2 \%)$ in the chronic group had cholecystitis; and $4(8.0 \%)$ patients in the acute group and 9 (6.4\%) in the chronic group had orchitis. Levels of IL-4, IL-6, IL-10, IL-17, IFN- $\gamma$, and TNF- $\alpha$ were all significantly higher in those with brucellosis than in the control group (all $P<0.05$; Table 2).

\section{Changes in cytokine levels in patients with acute and chronic brucellosis}

IL-6, IL-10, IL-17, IFN- $\gamma$, and TNF- $\alpha$ levels were significantly higher in the acute group than in the chronic group $(P<0.05$; Table 3$)$. We also found that the blood culture positive rate was significantly higher in the acute group than in the chronic group $(P<0.001)$, and PCT and CRP expression levels were significantly higher in the acute group than in the chronic group $(P<0.001)$, as shown in Table 3.

\section{The relationship between antibody titer and cytokine levels}

Patients were divided into a high titer group ( $>1: 100$, $n=79)$ and a low titer group ( $\leq 1: 100, n=112)$ according to the diagnostic level of the brucellosis antibody titer. We found that the blood culture positive rate and ESR, as well as the levels of RF, PCT, and CRP, were significantly higher in the high titer group $(P<0.001$; Table 4$)$. However, there was no difference in the levels of anti-O between the two groups. In addition, IL- 6 levels were significantly higher in the high antibody titer group than the low antibody titer group $(P<0.001$; Table 4$)$, but all other cytokine levels were similar.

\section{The relationship between cytokine expression and brucellosis}

We used logistic stepwise regression analysis to assess the relationship between the various cytokines and brucellosis. In our univariate analysis, IL-4, IL-6, IL-10, IL17 , IFN- $\gamma$, and TNF- $\alpha$ were risk factors for brucellosis (Table 5). In the multivariate logistic stepwise regression analysis, IL- 6 and INF- $\gamma$ were found to be independent risk factors for brucellosis after adjusting for age and gender.

\section{Discussion}

In this study, we examined the levels of six cytokines and inflammatory factors as well as clinical course characteristics of 191 patients with laboratory confirmed brucellosis. We found that IL-4, IL-6, IL-10, IL-17, IFN$\gamma$, and TNF- $\alpha$ levels were higher in those with brucellosis than in controls. With regard to disease progression, PCT and CRP levels were significantly higher in those with an acute infection compared to chronic cases.

Table 2 Comparison of cytokine levels in patients with brucellosis and controls

\begin{tabular}{|c|c|c|c|c|}
\hline Clinical indicators & $\begin{array}{l}\text { Case group } \\
(n=191)\end{array}$ & $\begin{array}{l}\text { Control group } \\
(n=60)\end{array}$ & $t / x^{2} / z$ & $P$-value \\
\hline Age (years), mean $\pm S D$ & $43 \pm 14$ & $40 \pm 11$ & $1.518(t)$ & 0.130 \\
\hline Gender, n (\%) & $137(70.2)$ & $40(66.7)$ & $0.609\left(x^{2}\right)$ & 0.609 \\
\hline IL-4 (pg/ml) & $2.74(0.97-6.25)$ & $0.56(0.53-0.64)$ & $8.379(z)$ & $<0.001$ \\
\hline IL-6 (pg/ml) & $34.10(13.05-60.8)$ & $0.78(0.41-2.52)$ & $7.183(\mathrm{z})$ & $<0.001$ \\
\hline IL-10 (pg/ml) & $1.83(1.15-2.75)$ & $0.89(0.77-1.13)$ & $4.857(z)$ & $<0.001$ \\
\hline IL-17 (pg/ml) & 6.77 (2.48-13.74) & $1.03(0.68-1.20)$ & $7.234(z)$ & $<0.001$ \\
\hline TNF-a (pg/ml) & $35.23(5.79-74.98)$ & $1.33(0.80-2.17)$ & $6.264(z)$ & $<0.001$ \\
\hline INF-y (pg/ml) & $212.96(42.30-436.72)$ & $1.69(1.36-1.89)$ & $7.683(\mathrm{z})$ & $<0.001$ \\
\hline
\end{tabular}

All data are expressed as mean (interquartile range), unless otherwise indicated 
Table 3 Comparison of cytokine levels in patients with acute and chronic brucellosis

\begin{tabular}{|c|c|c|c|c|}
\hline Clinical indicators & Acute group $(n=50)$ & Chronic group $(n=141)$ & $t / x^{2} / z$ & $P$-value \\
\hline Age (years), mean $\pm S D$ & $40 \pm 14$ & $44 \pm 14$ & $1.813(t)$ & 0.071 \\
\hline Gender, $n(\%)$ & $36(72.0)$ & $98(69.5)$ & $0.740\left(x^{2}\right)$ & 0.109 \\
\hline Brucellosis arthritis, $n$ (\%) & $23(46.0)$ & $89(63.1)$ & $4.460\left(x^{2}\right)$ & 0.035 \\
\hline Lumbar disc hyperplasia, $n$ (\%) & $23(46.0)$ & 76 (54.0) & $0.922\left(x^{2}\right)$ & 0.337 \\
\hline Chronic cholecystitis, $n$ (\%) & $11(22.0)$ & $20(14.2)$ & $1.658\left(x^{2}\right)$ & 0.198 \\
\hline Orchitis, n (\%) & $4(8.0)$ & $9(6.4)$ & $0.152\left(x^{2}\right)$ & 0.696 \\
\hline Blood culture, positive, $n(\%)$ & $20(40.0)$ & $23(16.5)$ & $11.508(z)$ & $<0.001$ \\
\hline $\mathrm{RF}(\mathrm{IU} / \mathrm{ml})$ & $7.2(3.8-9.9)$ & $6.2(3.7-9.8)$ & $0.633(z)$ & 0.526 \\
\hline $\mathrm{ESR}(\mathrm{mm} / \mathrm{h})$ & $25(15-40)$ & $17(7-37)$ & $2.040(z)$ & $<0.041$ \\
\hline anti-O (IU/ml) & $79(33-137)$ & $87(45-182)$ & $0.717(z)$ & 0.473 \\
\hline PCT (pg/ml) & $0.08(0.06-0.12)$ & $0.04(0.03-0.06)$ & $3.914(z)$ & $<0.001$ \\
\hline CRP (mg/L) & $12.6(5.0-30.8)$ & $3.3(1.2-16.2)$ & $3.931(z)$ & $<0.001$ \\
\hline IL-4 (pg/ml) & $4.03(1.29-8.08)$ & $2.02(0.96-5.90)$ & $1.874(z)$ & 0.061 \\
\hline IL-6 (pg/ml) & $65.32(36.27-68.60)$ & $29.38(11.30-53.09)$ & $3.683(z)$ & $<0.001$ \\
\hline IL-10 (pg/ml) & $2.38(1.51-3.34)$ & $0.89(0.77-1.13)$ & $3.350(z)$ & $<0.001$ \\
\hline IL-17 (pg/ml) & $11.98(3.92-16.49)$ & $5.27(2.24-12.49)$ & $2.856(z)$ & $<0.004$ \\
\hline TNF-a (pg/ml) & 50.88 (16.59-96.69) & $28.24(5.30-64.40)$ & $2.387(z)$ & $<0.017$ \\
\hline INF-y (pg/ml) & 319 (145.14-588.52) & $160.52(36.59-418.54)$ & $2.979(\mathrm{z})$ & $<0.003$ \\
\hline
\end{tabular}

All data are expressed as mean (interquartile range), unless otherwise indicated

CRP C-reactive protein, ESR Erythrocyte sedimentation rate, PCT Procalcitonin, RF Rheumatoid factor

The results from this study provide a basis for clinical diagnosis, assessment and case management of human brucellosis.

The gender and age distributions were consistent with previous studies $[14,15]$. The primary transmission route of brucellosis was through occupational exposure (78\%, 149/191), which is in accord with the results of epidemiological investigations in China [16, 17]. In other endemic countries, infections occur mostly due to ingestion of unpasteurized dairy products $[18,19]$. In the Sixth People's Hospital, many referred brucellosis patients were received. Therefore, most patients came to the clinic after several months of Brucella infection, when the disease had become chronic. The chronicity of

Table 4 Relationship between Brucella antibody titer and cytokine levels

\begin{tabular}{|c|c|c|c|c|}
\hline Clinical indicators & $\begin{array}{l}\text { Antibody titer } \leq 1: 100 \\
(n=112)\end{array}$ & $\begin{array}{l}\text { Antibody titer }>1: 100 \\
(n=79)\end{array}$ & $z$ & $P$-value \\
\hline Blood culture, positive, $n(\%)$ & $17(15.3)$ & $26(33.3)$ & 8.462 & $<0.004$ \\
\hline RF (IU/ml) & $3.0(0.8-9.7)$ & $13.6(3.0-31.4)$ & 4.496 & $<0.001$ \\
\hline $\mathrm{ESR}(\mathrm{mm} / \mathrm{h})$ & $15(7-31)$ & $27(15-46)$ & 4.245 & $<0.001$ \\
\hline anti-O (IU/ml) & $82.5(44.5-156.5)$ & $86.0(36.0-185.0)$ & 0.020 & 0.984 \\
\hline PCT (pg/ml) & $0.04(0.03-0.06)$ & $0.07(0.04-0.11)$ & 2.372 & $<0.017$ \\
\hline CRP (mg/L) & $3.03(0.85-9.70)$ & $13.65(2.97-31.43)$ & 4.496 & $<0.001$ \\
\hline IL-4 (pg/ml) & $2.84(0.98-6.16)$ & $2.69(0.97-6.25)$ & 0.946 & 0.068 \\
\hline IL-6 (pg/ml) & $30.46(11.30-50.02)$ & $46.20(17.72-79.69)$ & 2.840 & $<0.004$ \\
\hline IL-10 (pg/ml) & $1.66(1.14-2.52)$ & $1.98(1.15-3.13)$ & 0.156 & 0.156 \\
\hline IL-17 (pg/ml) & $6.54(2.09-13.37)$ & $6.77(2.80-15.27)$ & 0.942 & 0.346 \\
\hline TNF-a (pg/ml) & $37.13(6.05-61.89)$ & $36.23(5.79-86.44)$ & 0.751 & 0.452 \\
\hline INF-ץ (pg/ml) & 183.115 (41.59-413.25) & $270.91(47.03-538.5)$ & 1.620 & 0.105 \\
\hline
\end{tabular}

All data are expressed as mean (interquartile range), unless otherwise indicatedCRP C-reactive protein, ESR Erythrocyte sedimentation rate, $P C T$ Procalcitonin, $R F$ Rheumatoid factor 
Table 5 Multivariate logistic stepwise regression analysis of cytokine immunity and brucellosis

\begin{tabular}{|c|c|c|c|c|c|c|}
\hline \multirow[t]{2}{*}{ Variable } & \multirow[b]{2}{*}{ OR $(95 \% C)^{\mathrm{a}}$} & \multicolumn{2}{|c|}{ Single factor } & \multirow[b]{2}{*}{ OR $(95 \% C l)$} & \multicolumn{2}{|c|}{ Multiple factors } \\
\hline & & Wald & $P$-value & & Wald & $P$-value \\
\hline $\mid \mathrm{L}-4$ & $16.59(3.583-76.826)$ & 3.59 & $<0.001$ & & & \\
\hline IL-6 & $1.32(1.142-1.547)$ & 3.67 & $<0.001$ & $1.28(1.012-1.056)$ & 2.33 & $<0.012$ \\
\hline IL-10 & $4.793(2.106-10.907)$ & 3.74 & $<0.001$ & & & \\
\hline IL-17 & $11.14(3.459-35.898)$ & 4.04 & $<0.001$ & & & \\
\hline TNF-a & $1.32(1.080-1.635)$ & 2.69 & 0.007 & & & \\
\hline INF- $\gamma$ & $1.268(1.121-1.434)$ & 3.78 & $<0.001$ & $1.29(1.079-1.564)$ & 2.01 & $<0.006$ \\
\hline
\end{tabular}

${ }^{\mathrm{a}}$ Odds ratio $(O R)$ and $95 \%$ confidence interval $(95 \% \mathrm{Cl})$

Brucella infection may be related to its ability to escape the host's immune response [20].

We found that age and gender were not related to the pathogenesis of acute and chronic brucellosis. However, the complications of brucellosis did vary; for example, the prevalence of spondylitis and arthritis was higher in those with chronic brucellosis than in those with acute infection. We also found that the positive rate of blood culture was significantly higher in the acute group, indicating that the disease course is related to the severity of bacterial infection, as well as the intensity of immune response. PCT and CRP levels were also higher in those with an acute infection. These are consistent with other reports done in China and Turkey [21, 22].

After entering the human body, Brucella likely activates immune cells and promotes the production of cytokines by $\mathrm{T}$ lymphocytes. We found that IL-4, IL-6, IL10, IL-17, IFN- $\gamma$, and TNF- $\alpha$ levels were higher in patients with brucellosis than healthy controls, indicating a strong immune response was occurring. Indeed, previous studies have shown Brucella is effectively cleared through the secretion of IFN- $\gamma$, IL-2, and TNF- $\alpha$ by T helper (Th) 1 cells [23, 24].

We found that all cytokine levels were significantly higher in the acute group than in the chronic group, except for IL-4. IL-4 is the main cytokine released by Th2 cells to exert humoral immunity, which is not conducive to curing brucellosis [25].

With regards to the degree of infection (as assessed by brucellosis antibody titer), we found only IL-6 levels were altered. This indicates IL- 6 is the main factor for the chronicization of brucellosis infection. In addition, the positive rate of blood culture and ESR, as well as the RF, PCT, and CRP levels, were elevated in those with high antibody titer, reflecting the development of the disease $[26,27]$.

Overall our findings indicate the acute immune response to Brucella infection is more intense than during the chronic stage of the disease. Our results differ from those reported by Han et al. [12], who found that IFN- $\gamma$ levels were higher in chronic brucellosis than in acute brucellosis, and concluded that high IFN- $\gamma$ levels may be predictive of brucellosis chronicity. This may be due to different methods for case classification. In this study, we examined the relationship between brucellosis and cytokine levels, and found IL-4, IL-6, IL-10, IL-17, IFN- $\gamma$, and TNF- $\alpha$ were all risk factors for brucellosis, although only IL-6 and INF- $\gamma$ were independent risk factors for the severity of brucellosis. Finally, our results confirm previous data showing that Th1 cytokines help the body initially combat Brucella, while Th2 cytokines are involved as it progresses to brucellosis [28], although further research on the immune response to Brucella is warranted.

Our study was limited to the samples of brucellosis cases and controls. In the Sixth People's Hospital, many referred brucellosis patients were received. Therefore, a relatively large chronic disease population has been included in the current study. In next steps, we are going to divided the 141 chronic cases into two refined groups, i.e., 6 to 12 months and more than 12 months, to better confirm the reliability of the results.

\section{Conclusions}

Taken together, these findings demonstrate assessing cytokine levels in patients with brucellosis is not only useful for detecting the immune response, but can also be indicative of the severity of brucellosis. In particular, we propose IL- 6 and INF- $\gamma$ may be useful independent predictive factors in the clinical evaluation and diagnosis of brucellosis.

\section{Supplementary information}

Supplementary information accompanies this paper at https://doi.org/10. 1186/s40249-020-00666-7.

Additional file 1. Diagnostic Criteria for Brucellosis (WS 269-2019).

Acknowledgements

Not applicable.

Authors' contributions

ZQ L and GY L wrote the manuscript and carried out the analysis; $H$ J designed and supervised this study; $W W H, C Z, R Z, Y D L, F W$ and YQ investigated the cases; LD, DD Z, XJ Q and HG participated in laboratory works. All authors read and approved the final manuscript. 


\section{Funding}

This study was funded by grants from Major Infectious Diseases such as AIDS and Viral Hepatitis Prevention and Control technology major projects (2018ZX10101002 and 2018ZX10201002).

\section{Availability of data and materials}

Not applicable.

\section{Ethics approval and consent to participate}

The study protocol was reviewed and approved by the Sixth People's Hospital. Written informed consent has been obtained from the patients in accordance with the Declaration of Helsinki. We confirmed that the identification information of all participants (including patient names, ID numbers, home addresses and telephone numbers) would not be included in recordings, written descriptions or publications.

\section{Consent for publication}

Not applicable.

\section{Competing interests}

All authors declare that they have no competing interest.

\section{Author details}

'Department of Clinical Laboratory, Sixth People's Hospital, Urumqi, Xinjiang, Uygur Autonomous Region, China. ${ }^{2}$ State Key Laboratory for Infectious Disease Prevention and Control, Collaborative Innovation Center for Diagnosis and Treatment of Infectious Diseases, National Institute for Communicable Disease Control and Prevention, Chinese Center for Disease Control and Prevention, Beijing, China.

Received: 12 February 2020 Accepted: 23 April 2020

Published online: 07 May 2020

\section{References}

1. Cui BY. Concerned about the development of brucellosis and vaccine research in China. Chin J Endemiol. 2012;31(4):355-6. https://doi.org/10. 3760/cma.j.issn.1000-4955.2012.04.001 (in Chinese).

2. 10th National People's Congress of the People's Republic of China. Law of the People's Republic of China on the Prevention and Control of Infectious Diseases. 2004. https://doi.org/SUN:NYZS.0.2004-36-02V. (in Chinese), Accessed 25 Apr 2020.

3. Pappas G, Papadimitriou P, Akritidis N, Christou L, Tsianos EV. The new global map of human brucellosis. Lancet Infect Dis. 2006;6(2):91-9. https://doi.org/10.1016/S1473-3099(06)70382-6.

4. Cheville NF. Development, testing and commercialization of a new brucellosis vaccine for cattle. Ann N Y Acad Sci. 2000;916:147-53. https://doi.org/10.1111/j.1749-6632.2000.tb05285.x.

5. Lai S, Zhou H, Xiong W, Gilbert M, Huang Z, Yu J, et al. Changing epidemiology of human brucellosis, China, 1955-2014. Emerg Infect Dis. 2017;23(2):184. https://doi.org/10.3201/eid2302.151710.

6. Magnani DM, Harms JS, Durward MA, Splitter GA. Nondividing but metabolically active gamma-irradiated Brucella melitensis is protective against virulent $B$. melitensis challenge in mice. Infect Immun. 2009;77(11): 5181-9. https://doi.org/10.1128/IAl.00231-09.

7. Perkins SD, Smither SJ, Atkins HS. Towards a Brucella vaccine for humans. FEMS Microbiol Re. 2010;34(3):379-94. https://doi.org/10.1111/j.1574-6976. 2010.00211.x.

8. Racloz V, Schelling E, Chitnis N, Roth F, Zinsstag J. Persistence of brucellosis in pastoral systems. Rev Sci Tech. 2013;32(1):61-70. https://doi.org/10.20506/ rst.32.1.2186.

9. Ren DK, Chang Q, Shi ML, Li FK. Current situation of brucellosis in Xinjiang and countermeasures. Bull Dis Prev Control. 2008;23(5):36-7. https://doi.org/ 10.3969/j.issn.1000-3711.2008.05.017 (in Chinese).

10. Cui BY. Epidemic surveilance and control of brucellosis in China. Dis Surveill. 2007;22(10):649-51. https://doi.org/10.3784/j.issn.1003-9961.2007.10.001 (in Chinese).

11. Cui BY, Jiang H. Surveillance data of brucellosis in China, 2005-2016. Dis Surveill. 2018;33(3):188-92. https://doi.org/10.3784/j.issn.1003-9961.2018.03. 005 (in Chinese).
12. Han LH, Liu RH, Liu ZG, Cui BY. High level IFN- $\gamma$ may be one of the characteristics of chronic brucellosis. Chin J Zoonoses. 2017;33(8):53-6 doi: CNKI:SUN:ZRSZ.0.2017-08-010. (in Chinese).

13. The National Health Commission of the People's Republic of China. The Notice of the WS 269-2019 Diagnosis for Brucellosis. http://www.nhc.gov. cn/fzs/s7852d/201901/9493bdd1549b4908be18beb6007b009d.shtml. (in Chinese). Accessed 25 Apr 2020.

14. Shi Y, Lai S, Chen Q, Mu D, Li Y, Li X, et al. Analysis on the epidemiological features of human brucellosis in northern and southern areas of China, 2015-2016. Chin J Epidemiol. 2017;38(4):435-40. https://doi.org/10.3760/ cma.j.issn.0254-6450.2017.04.005 (in Chinese).

15. Memish Z, Mah MW, Mahmoud SA, Shaalan MA, Khan MY. Brucella bacteraemia: clinical and laboratory observations in 160 patients. J Inf Secur. 2000;40(1):59-63.

16. Lai S, Zhou H. Changing epidemiology of human brucellosis, China, 1955-2014. Emerg Infect Dis. 2017;23(2):184. https://doi.org/10.3201/eid2302.151710.

17. Wei $Z, M a L, Y u Y$, Nie X. Epidemiological analysis of brucellosis in Shanxi Province from 2004 to 2013. Chin J Endemiol. 2015;34(6):455-8. https://doi. org/10.3760/cma.j.issn.2095-4255.2015.06.018 (in Chinese).

18. Gur A, Geyik MF, Dikici B, Nas K, Cevik R, Sarac J, et al. Complications of brucellosis in different age groups: a study of 283 cases in southeastern Anatolia of Turkey. Yonsei Med J. 2003;44(1):33-44. https://doi.org/10.3349/ ymj.2003.44.1.33

19. Demirtürk N, Demirdal T, Erben N, Demir S, Asci Z, Kilit TP, et al. Brucellosis: a retrospective evaluation of 99 cases and review of brucellosis treatment. Trop Dr. 2008;38(1):59-62. https://doi.org/10.1258/td.2006.006266.

20. Elfaki MG, Alaidan AA, Al-Hokail AA. Host response to Brucella infection: review and future perspective. J Infect Dev Ctries. 2015;9(7):697-701. https:// doi.org/10.3855/jidc.6625.

21. Shi Y, Gao H, Pappas G, Chen Q, Li M, Xu J, et al. Clinical features of 2041 human brucellosis cases in China. PLoS One. 2018:13(11):e0205500.

22. Buzgan T, Karahocagil MK, Irmak H, Baran Al, Karsen H, Evirgen O, et al. Clinical manifestations and complications in 1028 cases of brucellosis: a retrospective evaluation and review of the literature. Int J Infect Dis. 2010; 14(6):e469-78. https://doi.org/10.1016/j.jijid.2009.06.031.

23. Celli J. Surviving inside a macrophage: the many ways of Brucella. Res Microbiol. 2006:157(2):93-8. https://doi.org/10.1016/j.resmic.2005.10.002.

24. Giambartolomei GH, Delpino MV, Cahanovich ME, Wallach JC, Baldi PC, Velikovsky CA, et al. Diminished production of T helper 1 cytokines correlates with T cell unresponsiveness to $\backslash \mathrm{r}$ Brucella $\backslash r$ cytoplasmic proteins in chronic human brucellosis. J Infect Dis. 2002;186(2):252-9.

25. Yingst S, Hoover DL. T Cell Immunity to Brucellosis. Crit Rev Microbiol. 2003; 29(4):313-31. https://doi.org/10.20506/rst.32.1.2190.

26. Baldwin $\mathrm{CL}$, Parent $\mathrm{M}$. Fundamentals of host immune response against Brucella abortus: what the mouse model has revealed about control of infection. Vet Microbiol. 2002;90(1-4):367-82. https://doi.org/10.1016/s03781135(02)00222-5.

27. Velásquez LN, Milillo MA, Delpino MV, Trotta A, Fernández P, Pozner RG et al. Brucella abortus down-regulates MHC class II by the IL-6dependent inhibition of CIITA through the downmodulation of IFN regulatory factor-1 (IRF-1). J Leukoc Biol. 2017;101(3):759-73. https://doi. org/10.1189/jlb.4A0416-196R.

28. Finlay BB, McFadden G. Anti-immunology: evasion of the host immune system by bacterial and viral pathogens. Cell. 2006;124(4):767-82 https://doi.org/10.1016/j.cell.2006.01.034.

Ready to submit your research? Choose BMC and benefit from:

- fast, convenient online submission

- thorough peer review by experienced researchers in your field

- rapid publication on acceptance

- support for research data, including large and complex data types

- gold Open Access which fosters wider collaboration and increased citations

- maximum visibility for your research: over $100 \mathrm{M}$ website views per year

At $\mathrm{BMC}$, research is always in progress.

Learn more biomedcentral.com/submissions 